\title{
Can the emergency response be coordinated?
}

\author{
Federico Laus \\ Department of Biomedical and Neuromotor Sciences, University of Bologna, Bologna, Italy \\ E-mail: federico.laus@unibo.it
}

Received 27 September 2021

Accepted 29 December 2021

\begin{abstract}
.
BACKGROUND: In the COVID-19 pandemic, coordination was certainly late, also due to the scarcity of information disseminated at the very beginning of the pandemic, when countries were inevitably taken by surprise. The lack of information, mainly attributable to the country from which everything seems to have started, has produced a huge delay and numerous uncertainties in the feedback of the WHO and international organizations.

OBJECTIVE: The inevitably relevant issue, from a legal point of view, concerns the legitimacy, formal or in any case shared, of the authority in charge of coordinating reactions and policies. The paper analyses the current legislation, soft and hard law, and the undertaken policies concerning emergency responses.

METHODS: International and EU legislation analysis.

RESULTS: The G20 understood that sustainable, flexible and agile funding systems for health emergencies are essential elements of pandemic prevention, preparedness and response. In EU there are many regulations about coordination and response to emergencies in practice in the EU and the Regulation (EU) 2021/522 (EU4Health programme), broadly extends the Union's competence in the field of health and has the objective of strengthening the Union's capacity for prevention, preparedness and rapid response in the event of serious cross-border threats to health.

CONCLUSIONS: It is essential to formalize, within international agreements, the institutionalization of relationships, procedures, and the possible recognition of the reference figure. If in the European Union, at least partially, the protocols are there (even if the COVID-19 emergency has blown them up in principle), certainly in relations with non-EU countries the story is complicated, requiring specific agreements. This is the goal of the path started by the Rome Declaration of 21 May 2021 within the G20 - Global Health Summit.
\end{abstract}

Keywords: Emergency response, institutions, G20, health, EU, WHO, international law, COVID-19

\section{Which emergency response?}

Discussing the COVID-19 pandemic, as well as illustrating its phases, seems superfluous since these are unfortunately well-known events. Instead, we need to analyse the level of coordination of countries around the world in their emergency response.

Coordination was certainly late, also due to the scarcity of information disseminated at the very beginning of the pandemic, when countries were inevitably taken by surprise. The lack of information, mainly attributable to the country from which everything seems to have started (that is, China), has produced a huge delay and numerous uncertainties in the feedback of the WHO and international organizations.

The first joint findings were achieved through the interruption of cross-border transport and, laboriously, with the sharing of data, studies and analyzes in general of the pandemic phenomenon and the disease. 
To date, there is still no common health protocol shared by all countries for the prevention and treatment of the disease. This is, of course, due to obvious differences in available resources, as well as in the absence of a sufficiently strong and competent international subject to rely on for the direction of interventions.

The inevitably relevant issue, from a legal point of view, concerns the legitimacy, formal or in any case shared, of the subject in charge of coordinating reactions and policies. It is therefore essential to formalize, within international agreements, the institutionalization of relationships, procedures, and the possible recognition of the reference figure.

If in the European Union, at least partially, the protocols are there (even if the COVID-19 emergency has blown them up in principle), certainly in relations with non-EU countries the story is complicated, requiring specific agreements. This is the goal of remedying the path started by the Rome Declaration of 21 May 2021 within the G20 - Global Health Summit, which is under consideration here.

\section{The emergency response in the $\mathbf{G 2 0}$ health declarations}

As anticipated, the Rome Declaration addressed the issue of emergency response, dedicating numerous steps of analysis and sharing among the intervening States to it. States shared the importance of highlevel political leadership for health emergency preparedness and response. In this sense, they expressed their intention to develop proposals for a possible international instrument or agreement on pandemic prevention and preparedness, in the context of the WHO, highlighting the efforts made by the WHO, the World Organisation for Animal Health, the Food and Agriculture Organisation of the United Nations, the United Nations Environment Programme and others to strengthen the implementation of the "One" approach. Health" through the dedicated group of high-level experts. According to point 1, States must enhance the existing multilateral health architecture for preparedness and response with an appropriately, sustainably and predictably funded, effective WHO at its centre. Furthermore, the Rome Declaration defined a series of principles and guiding commitments, aimed at promoting early warning systems, prevention, identification, coordinated response, resilience, and recovery from the current pandemic and potential future health emergencies.

These principles, to achieve adequate implementation, obviously require the adoption of effective governance, with entities equipped with the necessary tools to respond effectively and operate the interinstitutional coordination necessary to achieve the desired objectives. In particular, about point 13 of the Declaration, States have undertaken to coordinate pharmaceutical and non-pharmaceutical measures and emergency response (including online coordination of crisis and operational centres), in the context of a sustainable and equitable recovery, with investments in health, preparedness, and response, as well as policies based on scientific advice.

According to the commitment agreed by G20 participants, policies should accelerate progress towards achieving the Sustainable Development Goals, address the root causes of health emergencies, including the social determinants of health, poverty, structural inequalities, and environmental degradation, develop human capital, accelerate green and digital transitions and promote prosperity for all.

The declaration, therefore, underlines the role of social contexts and economic inequalities, as well as environmental conditions, in favoring emergencies, especially health ones. There is no doubt that the extent of an emergency is all the greater the worse the economic, social, and hygienic condition of the country. However, as highlighted during the COVID-19 pandemic, the countries with more resources must intervene to support these countries, not only in the implementation of principles of solidarity but also to contain, moderate, slow down the emergency and reduce the overflow of danger. 
In this sense, it is essential to identify a shared protocol and recognize prescriptivity, although, at the international level (unlike what, in part, can happen in the EU) the question that a sovereign country is unrestrainable, remains unresolved. This, for example, became evident about the implementation of the 1997 Kyoto Protocol on climate change, which received formal ratification by almost all signatories, but is still far from being fully implemented.

The complexity is represented, therefore, on the one hand, by the binding nature of a protocol and, on the other hand, by the transfer of funds and resources that has never taken place in a coordinated manner, based on the donations of the countries and bodies that have intervened in support of the countries affected by the emergencies (political, health and geological). Probably, the military response is the exception, as happened in Afghanistan, where NATO, on behalf of the UN Security Council, has led military missions for the last 20 years.

These circumstances were well known during the summit, so much so that the commitment was directed towards increasing the effectiveness of preparedness and response measures, supporting, and promoting meaningful and inclusive dialogue between communities and with communities. In particular, the intervening States committed themselves (with point 15) to address the need for enhanced, streamlined, sustainable and predictable mechanisms to finance long-term pandemic preparedness, prevention, detection, and response, as well as reactive capacity, capable of rapidly mobilising public and private funds and resources in a coordinated manner, transparent and collaborative and with a robust system of accountability and oversight. In addition, in implementation of a general principle of solidarity, made increasingly undeferrable by the pandemic, States have also committed themselves to join efforts to support the production and supply of vaccines and other supplies and/or the provision of funding for the purchase of vaccines to low- and middle-income countries, with particular regard, in fact, to the health emergency.

The principles expressed here must be extensible to every emergency, to identify a shared path to be started in every critical circumstance.

That the issue of funding and above all of the binding nature of an economic commitment, as an implementation of the principle of solidarity, represents a crucial junction, is also evident from the further emphasis placed in the declaration (in point 16) where States have undertaken to try to ensure the effectiveness of these financing mechanisms, including by leveraging mixed financing, innovative mechanisms, public, private and philanthropic sources and resources of international financial institutions. This is a very general commitment and open to any solution, given the uncertainty of the instruments that can be adopted. Certainly, one of the most positive aspects of the sharing of intentions and coordination would be the possibility of avoiding duplication of efforts.

Among the multilateral efforts announced would be the new general allocation of special drawing rights proposed by the IMF ${ }^{1}$, the ambitious reconstitution of IDA $20^{2}$, and the existing measures approved by the G20. All this, recalling the fundamental role of multilateral development banks and international organizations.

It seems useful, in this regard, to dwell on two aspects: the current role of the IMF and the Multilateral Development Banks, as well as their effectiveness in responding to emergencies. The IMF was established to promote economic and financial stability, including the aim of regulating economic coexistence and favouring developing countries.

\footnotetext{
${ }^{1}$ International Monetary Fund.

${ }^{2}$ International Development Association.
} 
Multilateral development banks, on the other hand, have as their main mandate to reduce poverty and promote economic development, as supranational institutions created by the sovereign states that are shareholders. Among these, we identify the European Investment Bank (EIB), the International Fund for Agricultural Development, the European Bank for Reconstruction and Development (EBRD), the World Bank (BM) (i.e., the International Bank for Reconstruction and Development - IBRD), the Inter-American Development Bank, the Asian Development Bank, the African Development Bank, the Caribbean Development Bank, as well as the Asian Infrastructure Investment Bank.

The system that arose from the Bretton Woods agreements of 1944, and now widely developed, had imagined the IMF and the international banks as institutions to support the development of territories and the reduction of poverty, certainly not bodies of reaction and economic coordination in international emergencies. It does not seem that, even for the peculiar statutes and for the differences in terms of shareholding, they can be invested with other functions shared by all. There would be a race between who must be recognized as the main international financial institution of a global nature (also for the wellknown struggle between China and the USA to assume financial leadership, even within these institutions, initially characterized by the US hegemonic role). However, although not directed to the regulation of the health emergency, these bodies represent a solid basis for the development of the infrastructures, necessary for the restart of the most affected and weakest countries, always intending to benefit from a global balance.

The insights and commitments of the Rome Declaration of 21 May 2021 reached a further level of maturity at the next G20 meeting on 5-6 September 2021. In the Declaration of 5-6 September, G20 Health Ministers call for continuity of concerted action towards a whole-of-government and whole-ofsociety response through good governance of health systems and immediate and medium-to-long term multi-sectoral actions on the social, economic, and environmental determinants of health, in every country, to strengthen prevention, detection, preparedness and response capacities, through a health-in-all policies approach. According to the statements of the g20, urgent coordination is needed to strengthen health systems, foster social well-being and community trust by implementing high-impact policies to protect people's health by working across all sectors for a "transformative resilience" approach.

The states intend to reinforce the global health architecture and governance based on a shared vision aiming at addressing challenges and at strengthening health systems and partnership for global health emergencies preparedness and response capacities, emphasizing the leading and coordinating role of the WHO on international health work in close collaboration with relevant stakeholders.

The declaration calls for collaborative multisectoral action to increase surveillance, strengthen prevention, preparedness and response for improved health outcomes and enhanced well-being for all, sustainable food systems, water and sanitation, and environmental protection.

As often highlighted, such a complex system needs a strong, trans-disciplinary, holistic One Health approach with political commitment for long-term investment. This would enable the states to strengthen and support resilient and sustainable health, social protection, and food systems, and to address risks emerging from the human-animal-environment interface, leveraging the technical leadership and coordinating role of the WHO, FAO, OIE and UNEP.

The commitment of G20 is to improve rapid and transparent research, data, information and material access and to share, in line with applicable laws and regulations at the national and international levels, necessary to prevent, detect, and respond to future potential health emergencies, and collectively resolve to strengthen research initiatives to better understand the links between human, animal (both domestic and wild) and environmental health, to enhance decision making based on solid scientific evidence.

In line with the EU Rapid Alert System, the G20 States commit to improving systems for the coordinated surveillance of zoonotic pathogens, AMR and environmental risks through cross-sectoral data integration 
on the national, regional and global level, and establishing early warning systems for communicable diseases, including zoonotic disease with pandemic potential and emergence of AMR by integrating data from across human, animal and the environmental sectors, as appropriate and feasible, with attention to digital transformation for enhanced governance and building off existing effective platforms.

But one of the most complex issues to discuss, from an economic, organizational, legal, and political point of view, is the coordinated and collaborative response.

In fact, the COVID-19 pandemic has highlighted the importance of investing in and protecting an adequate and well-trained health workforce and community-based health services, addressing a global shortage, increasing productive capacities to meet needs in the face of health risks and emergencies as well as insufficient human resource capacity at national and local levels. States aim to support multilateral mechanisms, such as the WHO, to facilitate assistance and response capacities, investing in the worldwide health and care workforce, to bring about the triple dividend of better health, acceleration of development, and advancements in social inclusion and gender equality, by developing mutually recognised competencies through education and training.

In line with the resolutions adopted by the 74th World Health Assembly on 31 May 2021 on 'Strengthening WHO preparedness for and response to health emergencies' (WHA74.7) and 'Protecting, safeguarding and investing in the health and care workforce' (WHA74.14) ${ }^{3}$, G20 members should expand and transform the recruitment, development, education, training, distribution, retention and financing of the health and care workforce. I.e., investing in human resources for health and in health and care workforce readiness, education, training, skills, and competencies, and build capacities for health preparedness and response, including through WHO's Global Outbreak Alert and Response Network (GOARN), pre-service education and lifelong learning.

What emerges clearly is the need to strengthen partnerships with WHO and the crucial role of the WHO Academy, which is also committed to develop One Health learning opportunities in conjunction with the OIE Training Platform and other potential partners, as well as other relevant training centres.

Back to the financial topic, the G20 understood that sustainable, flexible and agile funding systems for health emergencies are essential elements of pandemic prevention, preparedness and response and potential funding should add and complement rather than substitute existing streams for other development goals.

\section{The response to emergencies in the European Union}

As is well known, the very institution of the European Union and before the European Community came to create a union of intent and an economic community with shared rules. In the TFEU itself, the concept of solidarity is evident both in the introduction and in the substance. In fact, the intention is already expressed in the introduction to confirm the solidarity that binds Europe to the overseas countries and the desire to ensure the development of their prosperity under the principles of the Charter of the United Nations.

The concept of solidarity permeates the entire treaty, but Article 80 makes this clear, about policies relating to border controls, asylum and immigration, by establishing that those Union policies and their implementation are governed by the principle of solidarity and fair sharing of responsibility between the Member States, including financial responsibility.

\footnotetext{
${ }^{3}$ https://apps.who.int/gb/e/e_wha74.html.
} 
As regards the economic question, without prejudice to any other procedure provided for in the Treaties, the Council, on a proposal from the Commission, may decide, in a spirit of solidarity between the Member States, on measures appropriate to the economic situation, where serious difficulties arise in the supply of certain products, in particular in the energy sector. Thus, where a Member State is in difficulty or is seriously threatened with serious difficulties because of natural disasters or exceptional circumstances beyond its control, the Council, on a proposal from the Commission, may, under certain conditions, grant Union financial assistance to the Member State concerned.

Finally, by the solidarity clause, provided for in Article 222 TFEU, the European Union and the Member States act jointly in a spirit of solidarity where a Member State is the victim of a natural or man-made disaster.

These considerations must be considered in conjunction with what is dedicated to public health, precisely concerning health emergencies.

The European Union has developed a reaction, a shared protocol for health emergencies. In this sense, Article 168 TFEU provides that a high level of human health protection shall be ensured in the definition and implementation of all Union policies and activities.

Union action, which shall complement national policies, shall be directed towards improving public health, preventing physical and mental illness and diseases, and obviating sources of danger to physical and mental health. Such action shall cover the fight against the major health scourges, by promoting research into their causes, their transmission and their prevention, as well as health information and education, and monitoring, early warning of and combating serious cross-border threats to health.

The Union shall encourage cooperation between the Member States, also improving the complementarity of their health services in cross-border areas. Moreover, the Union and the Member States shall foster cooperation with third countries and competent international organisations in the sphere of public health.

The EU may also adopt incentive measures concerning monitoring, early warning of and combating serious cross-border threats to health, as then happened with the implementation of the rapid alert system on food safety.

The TEU also contains extensive references to the principle of solidarity, in particular with regard to the Union's external action (Article 21), in respect of which the Union defines and implements common policies and actions and works to ensure a high level of cooperation in all areas of international relations in order to help populations, countries and regions affected by natural or man-made disasters (letter g) and to promote an international system based on enhanced multilateral cooperation and good world governance (letter h).

Likewise, also regarding internal relations, Article 24 TEU provides that the Union is to conduct, establish and implement a common foreign and security policy based on the development of mutual political solidarity between the Member States, the identification of issues of general interest and the achievement of an ever-greater level of convergence of the actions of the Member States.

There are also numerous regulatory acts, hard and soft law, which with different nuances regulate the coordination and response to emergencies in practice in the EU and in relations with non-EU countries.

These include Council Regulation (EU) 2016/369 of 15 March 2016 on the provision of emergency support within the Union, the Commission Decision of 7 August 2015 on the establishment of Scientific Committees in the field of public health, consumer safety and the environment, the Council Conclusions on the economic crisis and healthcare of 10 July 2014, Regulation (EC) No 851/2004 of the European Parliament and of the Council of 21 April 2004 establishing a European Centre for Disease Prevention and Control. 
More recently, with specific regard to the COVID-19 affair, there have been several acts that have drawn up the reports and protocols during the emergency, such as the Commission Communication on coordinated economic response to the COVID-19 emergency of 13.3.2020, the Commission Communication on the coronavirus response of 2.4.2020, the Commission Communication on EU emergency assistance with regard to cross-border cooperation in the field of healthcare linked to the COVID-19 crisis of 3 April 2020, Commission Recommendation (EU) 2020/518 of 8 April 2020 on a common Union toolbox for the use and data to combat and exit the Covid-19 crisis, as well as many others aimed at.

Considering the growing relations and the evolution of the European Union market, even before the role of the State in the economy, it is necessary to think about the role of the European Union in supporting the Economy, through various projects such as the pandemic emergency purchase program (PEPP), the European Stability Mechanism (ESM) and the NextGenerationEU.

\section{Conflict of interest}

None to report. 